\title{
El impuesto predial en el marco del conflicto armado en Colombia: análisis de los alivios fiscales para víctimas del conflicto en Antioquia*
}

\section{Property tax in the armed conflict in Colombia: analysis of tax benefits for victims in Antioquia ${ }^{1}$}

\author{
JULiÁn ALBERTo ZAMBRANO SÁNCHEZ ${ }^{2}$
}

\section{Resumen}

Teniendo en cuenta el gran número de víctimas del conflicto armado, que han perdido sus tierras a raíz del conflicto armado, el presente texto pretende realizar un inventario de las principales normas que regulan beneficios fiscales en materia de impuesto predial para estas personas en Colombia. Para ello, se toma como ejemplo el caso del departamento de Antioquia. En tal sentido, la pregunta que se quiere resolver es la siguiente, ¿cuál es el marco jurídico de la tributación para víctimas del conflicto armado en Antioquia en relación con el impuesto predial?

Para dar respuesta a este interrogante, se realiza un análisis al artículo 121 de la Ley 1448 de 2011, Ley 417 de 1997 y, de manera general, a los acuerdos municipales que han regulado el tema en Antioquia.

Palabras clave: impuesto predial, víctimas del conflicto armado, beneficios fiscales.

\begin{abstract}
Colombia has a lot of armed conflict victims; they lost their properties because of armed conflict. The objective of this paper is review the most important norms about tax benefits for armed conflict victims. For this, the document uses Antioquia department how an example. In that way, the question who pretends answer is: What is the legal framework about property taxes of the victims in Antioquia?
\end{abstract}

* DOI: https://doi.org/10.18601/16926722.n10.08

${ }^{1}$ Síntesis del trabajo de grado "El impuesto predial en el marco del conflicto armado en Colombia: análisis de los alivios fiscales para víctimas del conflicto en Colombia”, por medio del cual el autor obtuvo su título de Magíster en Derecho con énfasis en Tributación en la Universidad Externado de Colombia.

${ }^{2}$ Abogado especialista en Derecho Tributario, Derecho Tributario Internacional y magíster en Derecho con énfasis en Tributación de la Universidad Externado de Colombia, actualmente se desempeña como consultor independiente y profesor de la Universidad de Antioquia. Correo electrónico: julianz1113@yahoo.com 
To answer this question, the text does an analysis of the 1448 Law of 2011, 417 Law of 1997 and main rules of the municipal agreements in Antioquia's towns.

Key words: Property tax, armed conflict victims, tax benefits.

\section{Sumario}

Introducción. I. Comentarios preliminares a la normatividad sobre víctimas y su relación con el derecho tributario. A. La víctima como sujeto de derechos. B. La restitución de tierras como mecanismo de protección de las víctimas de abandono y despojo. C. Comentarios preliminares sobre el impuesto predial. II. Régimen tributario en materia de impuesto predial para víctimas del conflicto armado en Antioquia. A. Exenciones de la Ley 418 de 1997. B. Alivios o exoneraciones de la Ley 1448 de 2011. C. Pronunciamientos de la Corte Constitucional sobre alivios fiscales en impuesto predial para víctimas del conflicto armado. D. Acuerdos municipales de beneficios fiscales en impuesto predial para víctimas del conflicto armado en Antioquia. 1. Acuerdos realizados a la luz de la Ley 418 de 1997. 2. Acuerdos en relación con la Ley 986 de 2005. 3. Incorporación del artículo 121 de la Ley 1448 de 2011 en los Estatutos Tributarios. E. Modelo de Acuerdo de la Unidad de Restitución de Tierras. Conclusiones. Referencias.

\section{Tabla de abreviaturas}

RTDAF Registro de Tierras Despojadas y Abandonadas Forzosamente

\section{Introducción}

El álgido conflicto armado por el cual ha pasado el Estado colombiano desde hace más de 60 años ha dejado un sinnúmero de víctimas. La Unidad para la Atención y Reparación Integral a las Víctimas (2015) ha reportado un saldo al primero de agosto de 2016 de 8.131.269 personas que han sido reconocidas como víctimas del conflicto armado.

En materia tributaria, las afectaciones que sufren las personas son diversas y de una intensidad tal que terminan afectando su mínimo vital. Piénsese, por ejemplo, en una persona que invierte la mayoría de su patrimonio en desarrollar una actividad económica relacionada con un bien inmueble. Lógicamente, el desempeño de su objeto le implica a esta persona soportar una carga tributaria que se ve reflejada en varios tipos de impuestos. Al poco tiempo de llevar a cabo esta misión, la persona se ve obligada a suspender de manera indefinida el desarrollo de su proyecto, como consecuencia de las alteraciones en el orden público de la región por el conflicto armado. Ante este escenario, a dicha persona le surgen las siguientes dudas: ¿qué tratamiento tributario especial merece, atendiendo lo ocurrido?, en relación con el predio abandonado, ¿hay alguna excepción o beneficio tributario, de carácter especial que le permita abstenerse de pagar el impuesto predial y otros tributos?

Con respecto al impuesto predial, la Ley 418 de 1997 permitió a los municipios crear exenciones de diversos impuestos, entre ellos el citado; sin embargo, dicha norma no tuvo gran acogida y fue con la Ley 1448 de 2011 que se estableció la obligación para los municipios de crear sistemas de alivios fiscales por concepto de este tributo. 
No obstante, la redacción de estos acuerdos municipales ha sido variable, además ha sometido el reconocimiento de estos beneficios a diferentes tipos de condiciones, algunas de ellas tan difíciles de cumplir que hace nugatorio el derecho de las víctimas.

En síntesis, la importancia del presente artículo radica en la necesidad de contribuir a la sistematización de las normas que reconocen beneficios tributarios en materia del impuesto predial a víctimas del conflicto. Lo anterior, con el fin de vislumbrar algunos de los problemas existentes en el reconocimiento de estos beneficios y así aportar a la construcción, desde el derecho tributario, de alternativas que sirvan para el restablecimiento de los derechos de las víctimas del conflicto armado, mediante la exaltación de algunos principios constitucionales, así como la flexibilización de algunas reglas.

De acuerdo con lo anterior, la pregunta que orientará la presente disertación será: ¿cuál es el marco jurídico de la tributación para víctimas del conflicto armado en Antioquia en relación con el impuesto predial?

Para dar respuesta al interrogante planteado, el presente artículo contará con dos grandes partes. La primera tendrá como objetivo la realización de un estado del arte sobre los conceptos preliminares necesarios para el entendimiento de la normatividad tributaria de las víctimas del conflicto armado.

Específicamente, se tratarán conceptos tales como, víctima, restitución de tierras, entre otros, los cuales son indispensables para entender la redacción y los alcances de las normas de carácter territorial que regulan los alivios fiscales para las víctimas del conflicto armado en Colombia. De igual manera, se realizarán algunos comentarios preliminares en torno al impuesto predial.
Posteriormente, se abordará el marco normativo existente para el reconocimiento de beneficios tributarios en materia de impuesto predial para las víctimas, partiendo de leyes tales como la Ley 418 de 1997 y la Ley 1448 de 2011. Luego se realizará un acercamiento a la jurisprudencia de la Corte Constitucional sobre el tema, para terminar con un análisis ejemplificativo de los acuerdos municipales que regulan este tema en los municipios de Antioquia.

\section{Comentarios preliminares a la normatividad sobre víctimas y su relación con el derecho tributario}

Durante el desarrollo del conflicto armado colombiano, el legislador se ha pronunciado en dos ocasiones sobre las medidas tributarias que se deben dar a las víctimas en materia de impuesto predial, aunque en contextos y con consecuencias totalmente diferentes. La primera vez lo hizo en el artículo 45 de la Ley 418 de 1997 que dispone: “(L)os Concejos [...] Municipales podrán establecer dentro de la órbita de su competencia exenciones de los impuestos de beneficencia, predial, [...], en beneficio de las víctimas de los actos a que se refiere el artículo 15 de esta ley (Ley 418, 1997, art. 45).

El segundo momento en que el legislador se pronunció sobre los beneficios fiscales para víctimas del conflicto armado fue en el artículo 121 de la Ley 1448 de 2011 que reza:

En relación con los pasivos de las víctimas, generados durante la época del despojo o el desplazamiento, las autoridades deberán tener en cuenta como medidas con efecto reparador, las siguientes: 
1. Sistemas de alivio y/o exoneración de la cartera morosa del impuesto predial u otros impuestos, tasas o contribuciones del orden municipal o distrital relacionadas con el predio restituido o formalizado. Para estos efectos las entidades territoriales establecerán mecanismos de alivio y/o exoneración de estos pasivos a favor de las víctimas del despojo o abandono forzado (Ley 1448, 2011, art. 121).

No obstante, los Consejos Municipales les han dado un contenido muy diverso a las citadas normas, regulando sus requisitos y efectos, e incluso, en muchos casos han omitido su aplicación. Por ello, partiendo de la pregunta de investigación propuesta en la introducción, de manera preliminar se pretende ahondar en algunos conceptos que serán fundamentales para entender el marco legal del impuesto predial para víctimas del conflicto armado.

Para ello, los dos primeros temas para abordar serán: (1) la víctima como sujeto de derechos, para luego hacer algunos comentarios sobre (2) la restitución de tierras y su procedimiento administrativo y judicial. Igualmente, no se deben perder de vista algunos conceptos de especial relevancia tributaria, los cuales servirán como elementos de análisis en la segunda parte para valorar el contenido de los acuerdos municipales que regulan los alivios de pasivos para víctimas o incluso la falta de regulación de estos. De tal manera, se realizarán algunos (3) comentarios preliminares sobre el impuesto predial.

\section{A. La víctima como sujeto de derechos}

A grandes rasgos, la aparición del concepto de víctima del conflicto armado como sujeto de derechos aparece a finales de la década de los noventa del siglo pasado, con la promulgación de la Ley 387 de 1997. Dicha norma trajo consigo una serie de medidas tendientes a brindar derechos a las víctimas de desplazamiento forzado. No obstante, el reiterado incumplimiento de los derechos consagrados dio lugar a que la Corte Constitucional en la Sentencia T-025 de 2004 declarara un estado de cosas inconstitucional respecto a los derechos de dicha población.

Desde la Sentencia T-025 de 2004 son muchos los cambios que se han dado en relación con la normatividad que rodea a las víctimas del conflicto; sin embargo, el cambio más importante que ha aportado tal fallo fue el reconocimiento de estos como sujetos de especial protección constitucional. Lo anterior, quiere decir que todas las entidades del Estado colombiano están en la obligación de prestar la mayor atención posible en la protección de los derechos fundamentales de ellos. De igual manera, la providencia en mención ha dado pie para la positivización de algunos principios que se han incorporado al ordenamiento jurídico. La más reciente e importante inclusión normativa, se dio con la Ley 1448 de 2011 , que en su artículo $3 .^{\circ}$ define como víctima del conflicto armado a toda aquella persona, natural o jurídica, que, sin ser combatiente, en el marco del conflicto armado ha sufrido algún tipo de perjuicio.

No obstante, de las múltiples afectaciones que puede sufrir una persona por culpa del conflicto armado, son muchas las que por falta de regulación se quedan sin ningún tipo de reconocimiento por parte del Estado. Pues, más allá de que las víctimas tengan derecho a la verdad, la justicia y la reparación, mientras no exista una ruta para la exigencia 
de estos derechos, solamente queda el mecanismo de la tutela.

\section{B. La restitución de tierras como mecanismo de protección de las víctimas de abandono y despojo}

La Ley 1448 de 2011 implementa un procedimiento administrativo, el cual es prerrequisito para acceder al proceso judicial. A este podrán acceder todas aquellas personas que, de conformidad con el artículo $3 .^{\circ}$ de la Ley 1448 de 2011, hayan sido víctimas de abandono y despojo con posterioridad al primero de enero de 1991, respecto a un bien inmueble sobre el cual ejercían la condición de propietario poseedor u ocupante.

El proceso de restitución de tierras fue diseñado para tener una duración inferior a un año; sin embargo, su inicio está sometido a la macrofocalización y a una posterior microfocalización. Ambos conceptos parten de la necesidad de iniciar procesos de restitución en el marco del conflicto, es decir, someten la implementación a los principios de gradualidad y progresividad.

Bajo esta premisa, la macrofocalización consiste en un área de terreno que es escogida por el Consejo de Seguridad Nacional, en la que, durante la vigencia de la norma, es decir, entre junio del 2011 y junio del 2021 , se van a adelantar los procesos de restitución de tierras. A su vez, las zonas microfocalizadas son áreas de terreno ubicadas dentro de las macrofocalizadas, que son determinadas mediante un acto administrativo emitido por una dirección territorial de la Unidad de Restitución de Tierras, basándose en la densidad de abandono y despojo, condiciones de seguridad y condiciones de retorno que la región ofrezca.
Si bien, la introducción de la macrofocalización y la microfocalización en desarrollo de los principios de progresividad y gradualidad son coherentes con la realidad del país, también es cierto que estos han limitado los derechos de las víctimas, prolongando por un tiempo indefinido el inicio de la etapa administrativa, que como se expresó es indispensable para determinar las medidas de reparación.

\section{Comentarios preliminares sobre el impuesto predial}

Para efectos de lo que le interesa a este escrito, no se pretende realizar un análisis riguroso de cada uno de los elementos que componen el impuesto predial, por el contrario, solamente se hará énfasis en el hecho generador. Así las cosas, es de resaltar que una característica fundamental de este tributo es que grava la propiedad inmueble como manifestación de la capacidad económica y contributiva (Acevedo, 2008, p. 127).

El impuesto predial es considerado un tributo de tipo real y como consecuencia de ello, se entiende que la persona que ostente la calidad de propietario o poseedor de este se encuentra en la capacidad de asumir el impuesto, en la medida de que su patrimonio es una muestra de capacidad contributiva (Acevedo, 2008; Parra, 2012 y Piza, 2010), sin consultar, en la mayoría de los casos, otros aspectos. No obstante, hay algunos casos en que este principio o regla general no se cumple, ya que por disposición del legislador o por voluntad de los Consejos Municipales, hay criterios que generan exenciones o no sujeciones al impuesto, más allá de la existencia de un bien inmueble, tema que será abordado más adelante. 


\section{Régimen tributario en materia de impuesto predial para víctimas del conflicto armado en Antioquia}

Ante el interrogante propuesto en el presente trabajo sobre cuál es el marco jurídico, que, en materia de impuesto predial, regula los derechos de las víctimas del conflicto armado en Antioquia, es menester adelantar desde este instante, que, salvo unos casos puntuales, la normatividad vigente no permite la materialización de los derechos de estas personas.

Para desarrollar la anterior tesis, se propone en el presente aparte abordar, en primera instancia, el contenido de los artículos 45 de la Ley 418 de 1997 y el 121 de la Ley 1448 de 2011. Posteriormente, se realizarán algunos comentarios sobre la jurisprudencia que se ha producido alrededor de este tema por parte de la Corte Constitucional. Por último, se ahondará de manera ejemplificativa en algunos acuerdos municipales que desarrollan las citadas leyes.

\section{A. Exenciones de la Ley 418 de 1997}

De la redacción del artículo 45 de la Ley 418 de 1997 son varios los aspectos de relevancia tributaria para las víctimas del conflicto armado. El primero de ellos, parte de la posibilidad que da la norma de que los Consejos Municipales establezcan exenciones en materia de impuesto predial, entre otros impuestos. Al plantearse como una alternativa y no como una obligación, el legislador es respetuoso de normas constitucionales que regulan la autonomía tributaria de los municipios $^{3}$. No obstante, tal disposición normativa no parece haber tenido eco en la mayoría de municipios, los cuales ignoraron o simplemente desconocieron esta disposición y evitaron que las víctimas pudieran acceder a mecanismos de exención de impuestos, como el predial.

Incluso, la Dirección de Apoyo Fiscal, del Ministerio de Hacienda, parecía desconocer del tema, cuando en el 2005 a la Secretaria de Hacienda, un municipio le consultó sobre la existencia de normas que les permitieran a los entes territoriales conceder exenciones de impuesto predial sobre predios rurales de víctimas de desplazamiento forzado. Ante este cuestionamiento simplemente se brindaron algunas indicaciones generales sobre las normas constitucionales que permiten este tipo de medidas y las restricciones jurisprudenciales existentes, sin mencionar esta Ley (Dirección de Apoyo Fiscal del Ministerio de Hacienda, 2005).

El segundo elemento de análisis del citado artículo recae sobre la exención en sí misma, toda vez que como se ha dicho, esta implica una actuación hacia futuro. Es decir, una vez el Consejo Municipal expide el acto administrativo reconociendo este derecho a las víctimas, solamente se podrá generar

\footnotetext{
${ }^{3}$ No se debe perder de vista que el artículo 294 de la Constitución Política, limita la posibilidad que tiene el legislador de regular exenciones y tratamientos preferenciales respecto de impuestos, tales como el predial, así las cosas, el poder tributario, típico del legislador, se traslada en este aspecto a los entes territoriales. Sobre este punto, la Corte Constitucional se ha pronunciado en sentencias tales como: C-510-92; C-517-92; C-004-93; C-027-93; C-040-93; C-126-93; C-19793; C-427-93; C-467-93; C-545-93; C-521-97; C-711-2001; C-1097-2001; C-226-04; C-992-04; C-448-05; C-812-09; C-333-10; C-260-15.
} 
el beneficio con posterioridad a la vigencia de este.

El tercer asunto problemático que trae el artículo 45 de la Ley 418 de 1997 recae sobre el concepto de víctima, el cual es remitido para su definición al artículo 15 de la misma ley. En ese orden de ideas, son víctimas para efectos de aplicación del artículo 45 de la Ley 418 de 1997 “Aquellas personas de la población civil que sufran perjuicios en su vida, o grave deterioro en su integridad personal o en sus bienes, por razón de atentados terroristas, combates, secuestros, ataques y masacres en el marco del conflicto armado interno".

Como se puede ver, en principio es claro que cualquier daño a la integridad, la vida o los bienes, es causal suficiente para ser reconocido como víctima en los términos de la Ley 418 de 1997, y así poder acceder a los beneficios tributarios consagrados en el artículo 45. Sin embargo, al no concretarse los hechos, que pueden ser reconocidos en el marco de la citada norma, puede prestarse para abusos tanto de la administración como de los contribuyentes. Lo anterior, debido a que por la redacción de la norma casi cualquier hecho puede ser considerado como victimizante o no, esta discusión fue abordada en la Sentencia C-914 de 2010 de la Corte Constitucional.

La cuarta dificultad que surge de la aplicación de la norma en estudio, radica en que esta únicamente consagra la posibilidad de que los municipios establezcan exenciones, lo cual soluciona casos futuros, pero deja sin regulación los casos precedentes en los que por culpa del conflicto armado los contribuyentes han tenido que dejar de cumplir con sus obligaciones formales y sustanciales.

\section{B. Alivios o exoneraciones de la Ley 1448 de 2011}

Contrario a lo que se pensaría, con la expedición de la Ley 1448 de 2011, la regulación en materia de alivios fiscales para víctimas del conflicto armado, en relación con el impuesto predial sufrió un gran retroceso en relación con las garantías de las víctimas, ya que, como se verá en los párrafos siguientes, el ánimo garantista del legislador se ve menguado por algunos conceptos que hacen que la exigencia de estos derechos no sea eficaz.

Como se dijo, el artículo 121 de la Ley de Víctimas y Restitución de Tierras, en principio, no pareciera querer restringir los derechos de las víctimas; sin embargo, lo hace. No obstante, antes de exponer las razones que justifican la anterior afirmación, es menester destacar dos aspectos que pueden ser benéficos para los contribuyentes, en relación con este tema: (i) la exigencia a los Consejos Municipales de regular los beneficios fiscales para las personas que más adelante se describirán, y (ii) entender el reconocimiento de este derecho a obtener estos alivios como una medida con efecto reparador.

Ante la exigencia formulada en el punto (i), se puede acoger dos posiciones. Si se parte de una tesis restrictiva de la facultad de los entes territoriales de definir los elementos del tributo, el efecto lógico sería que los Consejos Municipales están en la obligación de incorporar los alivios de pasivos por impuesto predial en su normatividad tributaria.

Por otro lado, si la posición que se acoge es la de una autonomía tributaria más amplia de los municipios, implicaría que la orden por parte del legislador no pasaría de ser un consejo para los Consejos Municipales, quienes en su arbitrio podrían optar por 
acoger dicha indicación totalmente, parcialmente o simplemente omitirla sin ninguna consecuencia jurídica.

En todo caso, sin importar la posición que se acoja, no se debe perder de vista que el artículo 121 de la Ley 1448 de 2011 desarrolla un derecho fundamental de las víctimas del conflicto armado, como lo es el derecho a la reparación, el cual ha sido conceptualizado por la Corte Constitucional desde sentencias como la T-025 de 2004. Esto debido a que se ha entendido que la restitución de tierras, como elemento del derecho de reparación, debe garantizar la entrega del bien saneado.

A pesar de las bondades que se enunciaron, el alivio de pasivos de la Ley de víctimas trae consigo otras restricciones que ponen a algunos contribuyentes que han sufrido perjuicios relacionados con el conflicto en una situación de inequidad respecto a otros. Las restricciones que impone la norma se pueden resumir en que:

(i) Reduce el universo de víctimas que puede acceder al beneficio, pues solamente está concedido para beneficiarios del proceso de restitución de tierras, es decir, únicamente víctimas de abandono y despojo.

(ii) Puede reducir su efectividad, al estar atado a los procesos de restitución de tierras, por ende, ligado a criterios de micro y macrofocalización para su otorgamiento.

(iii) Por último, los beneficios que consagran la norma son alivios y exenciones. Aquellos conceptos suscitan muchas dudas, puesto que pueden significar condonaciones de capital e intereses, solo intereses, congelación o refinanciación de las obligaciones tributarias, negociación, o simplemente una suspensión de términos.
Más allá de las interpretaciones o alcance que cada municipio le dé a esta disposición a través de sus acuerdos municipales, no se debe olvidar que, en algunos casos, los predios pasaron por el proceso de restitución de tierras. Lo anterior, es de una importancia inusitada, ya que los jueces civiles especializados en estos asuntos, han asumido su función como aplicadores de justicia transicional y, en ese sentido, han aplicado el artículo 121 de distintas maneras a saber:

Una primera aplicación adoptada por estos operadores jurídicos opta por simplemente instar a los Consejos Municipales para que den aplicación a los acuerdos municipales, que regulan los pasivos de las víctimas del conflicto y, en caso de no tenerlos, hacen el llamado de atención para que estos los creen (Tribunal Superior del Distrito Judicial de Antioquia, Sala Especializada en Restitución de Tierras, Sala Primera, 2013).

Otra posición totalmente diferente la han asumido algunos jueces y magistrados, quienes valiéndose de los principios que inspiran el proceso de restitución de tierras han decidido ordenar exenciones a favor de las victimas restituidas, por concepto de impuesto predial, aun cuando dicha medida no está consagrada en ningún acuerdo municipal en el respectivo ente territorial.

En igual sentido, otros jueces han optado en comparar el artículo 121 de la Ley 1448 de 2011 con la norma municipal sobre alivios de pasivos y han optado por aplicar el principio de favorabilidad a favor del contribuyente, reconociéndole mejores condiciones que las que trae consigo la norma municipal (Juzgado Primero Civil del Circuito Especializado en Restitución de Tierras de Santa Marta, 2013). 


\section{Pronunciamientos de la Corte \\ Constitucional sobre alivios fiscales \\ en impuesto predial para víctimas del conflicto armado}

La Corte Constitucional solamente se ha pronunciado dos veces sobre este tema (Sentencias T-347 de 2014 y T-911 de 2014). En ambas sentencias, la Corte recapituló los derechos de las víctimas, reiterando la condición especial por la que atraviesan y la obligatoriedad de las entidades del Estado de prestar una atención más ingente a las necesidades de este grupo poblacional. De igual manera, reafirmó el principio de solidaridad que debe primar con estas personas (Corte Constitucional, 2014).

Más adelante, aborda las particularidades del proceso de restitución de tierras para concluir en la obligación que el artículo 121 de la Ley 1448 de 2011 impone a los Consejos Municipales de crear instrumentos para exención y alivio de pasivos. Bajo este argumento, sin más consideraciones, la Corte dispuso la exoneración del pago del impuesto predial a favor del contribuyente por los periodos comprendidos entre 1998 y el 2013.

\section{Acuerdos municipales de beneficios} fiscales en impuesto predial para víctimas del conflicto armado en Antioquia

Como se ha visto, son muchas las discusiones que se pueden dar alrededor de los alivios de pasivos y exoneración en materia de impuesto predial para víctimas del conflicto armado. Sin embargo, estas se quedan cortas si se comparan con las que pueden surgir con la aplicación de los acuerdos municipales que las desarrollan. Por eso, en este aparte se pretende mostrar de manera ejemplificativa el contenido de algunos de estos instrumentos que tratan el tema en los municipios del departamento de Antioquia.

Con tal fin, se hizo una revisión inicial por medios electrónicos con el fin de rastrear que municipios han cumplido con la obligación de expedir el acuerdo municipal que permita a las víctimas del conflicto acceder a beneficios fiscales. Causa sorpresa que de los 125 municipios que tiene el departamento Antioquia, solo 36 de ellos hayan acogido esta imposición normativa. Esto indica que el $71,2 \%$ del departamento de Antioquia se encuentra omisos, tal como se puede evidenciar en la figura 1 .

\section{Figura 1. Municipios antioqueños que cuentan con acuerdos que establecen beneficios fiscales para víctimas del conflicto armado}

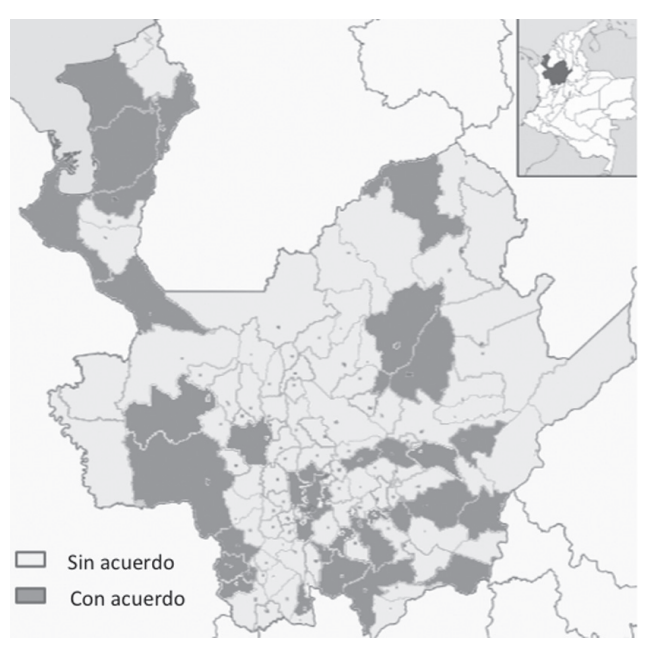

Fuente: elaboración propia

La anterior figura muestra una situación preocupante, pues la gran mayoría de municipios de Antioquia no han cumplido con la responsabilidad de crear mecanismos fiscales que permitan reparar a las víctimas, que a raíz del conflicto armado se han visto 
en la obligación de cesar sus pagos por concepto de impuesto predial. Lo que significa que los funcionarios de la administración de cada ente territorial se encuentran en la obligación de continuar con los procesos de determinación y cobro de este tributo sin ningún tipo de consideración especial sobre estas personas, que no cuentan con más alternativas que la vía constitucional de la acción de tutela.

Ahora bien, para entrar en el análisis de forma general de los 36 acuerdos municipales que regulan los beneficios fiscales en materia de impuesto predial para víctimas del conflicto armado, se dividirán estos en cuatro grandes grupos: (1) los que se fundamentan en la Ley 418 de 1997, (2) los que desarrollan la Ley 986 de 2005, (3) los que incluyen los beneficios de la Ley 1448 de 2011 en sus respectivos Estatutos Tributarios, y (4) los que acogieron el proyecto de acuerdo propuesto por la Unidad de Restitución de Tierras.

\section{Acuerdos realizados a la luz de la Ley 418 de 1997}

Durante los casi veinte años de la vigencia de la Ley 418 de 1997, solo un municipio decidió hacer uso de este instrumento normativo para favorecer a las víctimas del conflicto armado. A través del Acuerdo 007 del 28 de febrero de 2009, el municipio de Frontino reguló los beneficios fiscales a los que tendrían derecho este grupo de personas en materia de impuesto predial. No obstante, dicha norma no se encuentra vigente, pues el plazo para acogerse al beneficio expiró.

\section{Acuerdos en relación con la Ley 986 de} 2005

Durante el desarrollo del texto, se ha omitido de manera intencional hacer cualquier referencia a la Ley 986 de 2005, por medio de la cual se adoptaron algunos mecanismos de protección a las víctimas del secuestro y que por disposición de la Sentencia C-394 de 2007 fue ampliada a víctimas de desaparición forzada. La razón para ello, radica en que el artículo 20 de la mentada norma no establece un verdadero beneficio tributario, únicamente establece una suspensión de términos común al secuestrado o desaparecido y a la administración tributaria, en las obligaciones de pago, declaración, por un lado, y en las facultades de revisión, sanción y ejecución, por el otro lado.

De los 36 acuerdos municipales promulgados con el fin de establecer beneficios fiscales en materia de impuesto predial para las víctimas del conflicto, seis municipios ${ }^{4}$ optaron por suspender términos de la misma manera que lo reguló la Ley 986 de 2005. Salvo pequeñas modificaciones en torno a los periodos en que se extiende la suspensión de los términos y la posibilidad de que bajo este beneficio se cobijen los familiares más cercanos; la redacción de las normas territoriales no dista mucho de lo consagrado en la citada ley.

\section{Incorporación del artículo 121 de la Ley 1448 de 2011 en los Estatutos Tributarios}

Teniendo en cuenta la posición tan importante que tiene la Unidad de Restitución de

${ }^{4}$ Bello, Caldas, Envigado, Hispania, Valparaíso y Medellín. 
Tierras en la gestión para que los municipios creen alivios de pasivos en materia de impuesto predial, dicha entidad diseñó un proyecto de acuerdo municipal y de exposición de motivos para que los municipios lo estudiarán y decidieran sobre la viabilidad de promulgarlos.

Este modelo de acuerdo pretendía regular los beneficios para víctimas del conflicto de manera separada de los Estatutos Tributarios; sin embargo, hubo municipios que lo incorporaron en estos cuerpos normativos con algunas variaciones que se pasarán a estudiar. En total fueron nueve los municipios que escogieron esta forma de establecer este beneficio tributario.

En la redacción del articulado se puede observar dos modelos y un caso atípico, el del municipio de Maceo. Este último trae en su Estatuto Tributario una norma que le permite a aquellas personas naturales que sean beneficiarias del programa de restitución de tierras en el marco de la Ley 1448 de 2011, acceder a un descuento del $8 \%$ en el pago del impuesto predial, desde el 2014 y hasta la vigencia de esta norma, es decir hasta el 2021 (Consejo Municipal de Maceo, 2013). A pesar de lo anterior, no se hace mención a los impuestos que no se han pagado por culpa del conflicto y mucho menos a los intereses y sanciones.

Por su parte, otro grupo de municipios ${ }^{5}$, en idéntica redacción establecieron un sistema de alivio de pasivos para víctimas de abandono, desplazamiento y despojo, al cual pueden acceder aquellas personas que acrediten la inscripción en el Registro Único de
Víctimas -RUV- o en el Registro de Tierras Despojadas y Abandonadas Forzosamente -RTDAF-, situación que debe ser avalada por la autoridad municipal. Los beneficiarios de la norma pueden acceder a las siguientes prerrogativas:

Causación del impuesto: no se causará el impuesto predial desde la entrada en vigencia de la respectiva norma, hasta que se termine la vigencia de la norma que creó el beneficio $^{6}$; sin que exceda de un año a partir de la restitución en términos de la Ley 1448 de 2011.

Sanciones e intereses: de igual forma no se generan intereses y sanciones por los impuestos causados antes de la vigencia de la norma y que no hayan sido pagados a raíz de los hechos victimizantes.

Suspensión de términos: asimismo se suspenden los términos para el contribuyente y para la administración en

los procedimientos de corrección, información, revisión o sanción, discusión de los actos administrativos, solicitud de devoluciones, emplazamientos y los relativos a la extinción de obligaciones tributarias por concepto del impuesto predial unificado y los demás impuestos, tasas y contribuciones relacionadas con el predio durante este período (Consejo Municipal de Barbosa, 2014; Consejo Municipal de Sabaneta, 2014; Consejo Municipal de Santa Fe de Antioquia, 2015).

Cobro coactivo: finalmente, la norma prohíbe a la administración iniciar procesos

\footnotetext{
${ }^{5}$ (Consejo Municipal de Barbosa, 2014; Consejo Municipal de Sabaneta, 2014; Consejo Municipal de Santa Fe de Antioquia, 2015).

${ }^{6}$ En la norma de Sabaneta, expresamente dispone que el beneficio tendrá una vigencia de diez años, mientras que en los demás no se dice nada, por lo que, al estar incorporado al Estatuto Tributario, se debe entender que la vigencia es la misma de esta última norma.
} 
de cobro coactivo frente a las víctimas que cumplan con los requisitos citados, también se deben suspender los procesos ya iniciados.

Por último, hay un grupo de cinco municipios $^{7}$ que reguló los beneficios para este tipo de contribuyentes de una manera más restrictiva, pues a pesar de cubrir los mismos tipos de hechos victimizantes y de exigir los mismos requisitos para acreditar la condición de víctima ${ }^{8}$, que los enunciamos anteriormente, los beneficios se limitan a:

Suspensión de término: al igual que en el anterior grupo de acuerdos, una vez solicitado el beneficio y verificado el supuesto de hecho, se suspenden los términos para el contribuyente y para la administración durante el tiempo de ocurrencia de los hechos punibles, siempre que la obligación no la haya cumplido un agente oficioso.

Sanciones e interese moratorios: una vez reconocida la suspensión, no se causarán intereses ni sanciones durante el periodo que dure esta.

Además de regresiva, en el sentido de que no reconoce ningún beneficio real, la redacción de la norma es desafortunada, pues enlaza la duración de la suspensión a la ocurrencia de hechos punibles y no a la situación de la víctima. Así las cosas, lleva al interprete a la difícil situación de interpretar y en algunas situaciones tipificar la conducta para saber si es de ejecución permanente o sucesiva y, de esa manera, determinar el término por el cual se debe suspender los términos.

\section{E. Modelo de Acuerdo de la Unidad de Restitución de Tierras}

Como se ha indicado en diferentes apartes de este texto la Unidad de Restitución de Tierras diseñó un proyecto de acuerdo, acompañado de un proyecto de exposición de motivos. De este último, vale la pena resaltar que la propuesta está dirigida única y exclusivamente a los contribuyentes cuyos bienes hayan sido objeto de sentencia de restitución de tierras. Adicionalmente propone la condonación del impuesto predial y la exención de este durante los dos años siguientes a la restitución del inmueble, que es más o menos el periodo que considera necesario dicha entidad para el restablecimiento de la capacidad contributiva de la víctima.

Por su parte el proyecto de acuerdo municipal ratifica que los beneficiarios de este tipo de medidas son los contribuyentes del impuesto predial que sean víctimas del conflicto armado y que en razón de una sentencia de restitución de tierras o mediante un acto administrativo de inclusión en el RTDAF, se les reconozca tal condición.

En lo que tiene que ver con beneficios, se reconoce la condonación de impuestos, intereses corrientes y moratorios, así como gastos derivados de los procesos de cobro ${ }^{9}$ desde la fecha del desplazamiento, abandono o despojo, reconocido por el acto administrativo o sentencia judicial; hasta la fecha de la restitución efectiva del bien inmueble o la fecha de retorno. Asimismo, se reconoce

\footnotetext{
7 (Consejo Municipal de Betania, 2014; Consejo Municipal de Guadalupe, 2013; Consejo Municipal de San Pedro de Urabá, 2013; Consejo Municipal de Urrao, 2014; Consejo Municipal de Puerto Nare, 2013; Consejo Municipal de Medellín, 2012).

${ }^{8}$ Salvo Urrao que adicionalmente exige sentencia ejecutoriada de un juez de Restitución de Tierras para el reconocimiento del beneficio.

${ }^{9}$ Salvo lo que tiene que ver con gastos de apoderados, los cuales son asumidos por la Unidad de Restitución de Tierras.
} 
una exoneración en el pago de este tributo por un periodo de dos años. Para el reconocimiento de estos beneficios, es necesario que el contribuyente figure en la parte resolutiva de la sentencia de restitución o del acto administrativo que hace el reconocimiento del hecho victimizante en relación con el predio. A pesar de esto, el modelo de acuerdo fue acogido, en términos generales, por veinte municipios ${ }^{10}$, los cuales incluyeron cambios de acuerdo con sus necesidades.

\section{Conclusiones}

Como se anunció desde el principio del segundo aparte, la tesis central del presente trabajo consistía en demostrar que las normas que regulaban los beneficios fiscales en materia de impuesto predial para las víctimas del conflicto armado no cumplían con el fin de satisfacer los derechos de estas personas a la reparación y el goce efectivo de sus derechos.

Son varios los argumentos que pueden dar sustento a la anterior afirmación, que van desde el desconocimiento y la omisión de las entidades sobre el tema, pasando por la regulación y llegan a la aplicación de la norma. Este último aspecto, fue omitido pues implicaría otro tipo de investigación.

En ese orden de ideas, se puede evidenciar las problemáticas que se presentan en la conceptualización del beneficiario de estas medidas y los alcances del beneficio. Todo esto lleva a dos grandes conclusiones: la primera, es que los beneficios fiscales para víctimas del conflicto armado, si bien cuentan con desarrollo legal, esta se queda corta en regular algunos aspectos de suma relevancia y sobre todo es restrictiva en el reconocimiento de derechos. Asimismo, las normas adolecen de difusión y sobre todo concientización a los entes territoriales, para que acompañen esta propuesta por convicción y no por obligación.

Muestra de esto último, lo refleja el departamento de Antioquia, el cual de sus 125 municipios, únicamente 36 cuentan con Acuerdos Municipales que regulen estos beneficios. De estos 36, hay catorce municipios que cuentan con normas al respecto que no están vigentes, o que simplemente establecen suspensión de términos comunes a la administración y al contribuyente, que se reitera no constituye beneficio alguno. Siendo esto así, se puede afirmar que en Antioquia solamente 22 municipios están cumpliendo con dicha norma, lo que se traduce en un porcentaje irrisorio del $17,6 \%$.

Obsérvese como para poder acceder a estos beneficios tributarios, hoy en día, una persona promedio que ha sufrido un hecho victimizante debe sortear todos estos límites:

i. Ser víctima únicamente por la ocurrencia de abandono, despojo y eventualmente secuestro y desaparición. Dejando de lado 
a aquellos contribuyentes que han perdido su capacidad adquisitiva a raíz del conflicto y que han sufrido otro tipo de daños, como homicidio, extorsión, entre otros.

ii. Realizar una declaración ante la Unidad de Restitución de Tierras para ser inscrito en el Registro de Tierras Despojadas y Abandonadas.

iii. Esperar a que la zona donde se encuentra el bien inmueble sobre el cual recae el impuesto predial, sean macro y microfocalizadas. Lo cual, basados en el principio de progresividad y gradualidad, podría extender la espera hasta el 2021.

iv. Esperar la resolución del procedimiento administrativo de restitución de tierras, en el que se incluya el predio en el registro.

v. En algunos casos, esperar a que sea proferida la sentencia por parte de los jueces de Restitución de Tierras.

vi. Verificar si el municipio donde se encuentra el predio cuenta con Acuerdo $\mathrm{Mu}$ nicipal que brinde beneficios fiscales a las víctimas del conflicto armado.

vii. En caso de que lo tenga, determinar si las medidas consagradas están vigentes.

viii. Cumplir con los requisitos que imponga la norma local para el reconocimiento de los derechos, que no necesariamente implican la condonación o exención total de lo adeudado.

Como se puede observar, con las normas citadas se está sometiendo a este tipo de contribuyentes a cumplir con una carga muy alta de requisitos formales, que no necesariamente van a redundar en un beneficio fiscal. Es más, es muy posible que esa persona ni siquiera tenga una medida adecuada para resolver su situación tributaria en relación con el impuesto predial.

La segunda gran conclusión, es que el derecho a obtener beneficios fiscales por parte de las víctimas, ya sea de condonación o de exención, está íntimamente ligado al derecho fundamental a la restitución de tierras, además de otros como lo son el mínimo vital, pues sin el saneamiento de los pasivos que recaen sobre el predio, no es posible garantizar el goce efectivo de derechos.

En consecuencia, se debe propender porque este derecho abarque situaciones similares de victimización a las del abandono o el despojo, como cuando un secuestrado o un desaparecido pierden la capacidad contributiva. De igual manera, se debe concientizar a los Consejos Municipales para que incluyan normas que verdaderamente otorguen beneficios tributarios como condonaciones por impuestos, intereses y sanciones dejados de pagar por culpa del conflicto armado y sobre todo la exoneración del impuesto a aquellas personas que no estén en capacidad de disponer del inmueble por los mismos motivos ya expresados. 


\section{Referencias}

Acevedo, S. (2008). Impuesto predial. En J. Piza (Coord.), Régimen impositivo de las entidades territoriales en Colombia. Bogotá: Universidad Externado de Colombia.

Agencia Presidencial para la Acción Social y la Cooperación Internacional y Proyecto Protección de Tierras y Patrimonio de la Población Desplazada (2010). Experiencias de documentación y recuperación de tierras abandonadas y despojadas con ocasión del conflicto armado. Recuperado de file:///F:/Bogot\%C3\%A1/Trabajo\%20 de $\% 20$ grado/Ojo $\% 20$ Experiencias $\% 20 \mathrm{de} \% 20$ documentaci\%C3\%B3n $\% 20 \mathrm{y} \% 20$ recuperaci $\% \mathrm{C} 3 \% \mathrm{~B} 3 \mathrm{n} \% 20 \mathrm{de} \% 20$ tierras\%20abandonadas.pdf

Alexy, R., y Bernal, C. (2004). Epílogo a la teoría de los derechos fundamentales. Madrid: Colegio de registradores de la propiedad, mercantiles y bienes muebles de España.

Congreso de la República. (6 de julio de 1983). Por la cual se fortalecen los fiscos de las entidades territoriales y se dictan otras disposiciones [Ley 14 de 1983]. DO: 36288.

Congreso de la República. (18 de diciembre de 1990). Por la cual se dictan normas sobre catastro e impuestos sobre la propiedad raíz, se dictan otras disposiciones de carácter tributario, y se conceden unas facultades extraordinarias. [Ley 44 de 1990]. DO: 39607.

Congreso de la República. (18 de julio de 1997). Por la cual se adoptan medidas para la prevención del desplazamiento forzado; la atención, protección, consolidación y estabilización socioeconómica de los desplazados internos por la violencia en la República de Colombia. [Ley 387 de 1997]. DO: 43091.

Congreso de la República. (26 de diciembre de 1997). Por la cual se consagran unos instrumentos para la búsqueda de la convivencia, la eficacia de la justicia y se dictan otras disposiciones. [Ley 418 de 1997]. DO: 43201.

Congreso de la República. (26 de agosto de 2005). Por medio de la cual se adoptan medidas de protección a las víctimas de secuestro y sus familias, y se dictan otras disposiciones. [Ley 986 de 2005]. DO: 46015.

Congreso de la República. (29 de diciembre de 2010). Por medio de la cual se dictan normas tributarias de control y para la competitividad. [Ley 1430 de 2010]. DO: 47937.

Congreso de la República. (10 de junio de 2011). Por la cual se dictan medidas de atención, asistencia y reparación integral a las víctimas del conflicto armado interno y se dictan otras disposiciones. [Ley 1448 de 2011]. DO: 48096.

Congreso de la República. (18 de diciembre de 2014). Por medio de la cual se prorroga la Ley 418 de 1997 , prorrogada y modificada por las Leyes 548 de 1999, 782 de 2002, 1106 de 2006 y 1421 de 2010. [Ley 1738 de 2014]. DO: 49369.

Consejo Municipal de Abejorral. (1. ${ }^{\circ}$ de junio de 2013). Mediante el cual se establece el sistema de alivio de la cartera morosa del impuesto predial $\mathrm{u}$ otros impuestos tasas y contribuciones del orden municipal a las víctimas del despojo o desplazamiento forzado relacionadas con el predio restituido o señalado. [Acuerdo municipal n. ${ }^{\circ}$ 010 de 2013].

Consejo Municipal de Amalfi. (13 de junio de 2013). Por el cual se establece la condonación y exoneración del impuesto predial a favor de la población en situación de desplazamiento forzado, despojo y abandono de tierras. [Acuerdo municipal n. ${ }^{\circ} 11$ de 2013].

Consejo Municipal de Anorí. (25 de mayo de 2015). Por el cual se establece la condonación y exoneración del impuesto predial, tasas y otras contribuciones a favor de los predios restituidos o formalizados en el marco de la Ley 1448 de 2011. [Acuerdo municipal n. ${ }^{\circ} 009$ de 2015].

Consejo Municipal de Caucasia. (26 de diciembre de 2014). Por el cual se establece la condonación y exoneración del impuesto predial, tasas y otras contribuciones a favor de los predios restituidos o formalizados en el marco de la Ley 1448 de 2011. [Acuerdo municipal n. ${ }^{\circ} 028$ de 2014]. 
Consejo Municipal de Ciudad Bolívar. (19 de mayo de 2013). Por medio del cual se conceden facultades al ejecutivo para la condonación y exoneración del impuesto predial a las personas víctimas del desplazamiento forzado y otros delitos. [Acuerdo municipal n. ${ }^{\circ} 004$ de 2013].

Consejo Municipal de El Carmen de Viboral. (30 de noviembre de 2013). Por medio del cual se condona del pago de impuesto predial unificado los predios de las víctimas del conflicto armado del municipio de El Carmen de Viboral. [Acuerdo municipal n. ${ }^{\circ} 017$ de 2013].

Consejo Municipal de El Santuario. (22 de agosto de 2015). Por el cual se establece la condonación del impuesto predial, tasas y otras contribuciones a favor de los predios restituidos o formalizados en el marco de la ley 1448 de 2.011. [Acuerdo municipal n. ${ }^{\circ} 016$ de 2015].

Consejo Municipal de Envigado. (27 de diciembre de 2013). Por medio del cual se modifica el Acuerdo 062 de 2008 estatuto tributario municipal de Envigado y se dicta otras disposiciones. [Acuerdo municipal No. 052 de 2013].

Consejo Municipal de Frontino. (28 de febrero de 2009). Por medio del cual se otorgan unas exenciones y condonaciones a las personas víctimas del desplazamiento, respecto a la causación y el pago del impuesto predial. [Acuerdo municipal n. ${ }^{\circ} 007$ de 2009].

Consejo Municipal de Granada. (5 de diciembre de 2013). Por el cual se establece la condonación y exoneración del impuesto predial, tasas y otras contribuciones a favor de los predios restituidos en el marco de la Ley 1448 de 2011. [Acuerdo municipal n. ${ }^{\circ} 46$ de 2013].

Consejo Municipal de Itagüí. (27 de diciembre de 2013). Por el cual se establece la condonación y exoneración del impuesto predial a favor de los predios restituidos o formalizados en el marco de la Ley 1448 de 2011. [Acuerdo municipal n. ${ }^{\circ} 007$ de 2009].

Consejo Municipal de La Ceja. (22 de diciembre de 2014). Por medio del cual se adopta y se da aplicación a la Ley 1448 de 2011, la Ley 1592 de 2012 y su Decreto Reglamentario 3011 de 2013. [Acuerdo municipal n. ${ }^{\circ}$ 007 de 2014].

Consejo Municipal de Medellín. (23 de diciembre de 2012). Por medio del cual se expide la normativa sustantiva aplicable a los ingresos tributarios en el Municipio de Medellín. [Acuerdo municipal n. ${ }^{\circ} 64$ de 2012].

Consejo Municipal de Montebello. (28 de diciembre de 2013). Por el cual se adiciona y modifica el Acuerdo Municipal 005 de 2012 que establece la condonación y exoneración del impuesto predial, a las personas víctimas del desplazamiento forzado y otros delitos. [Acuerdo municipal n. ${ }^{\circ} 14$ de 2013].

Consejo Municipal de Salgar. (8 de junio de 2013). Por el cual se otorgan exenciones y condonaciones a las personas en condición de desplazamiento forzado, respecto a la causación y pago del impuesto predial. [Acuerdo municipal n..$^{\circ} 032$ de 2013].

Consejo Municipal de Santa Fe de Antioquia. (Diciembre de 2013). "Por medio del cual se adopta el Código de Rentas, la normatividad Sustantiva tributaria, el procedimiento tributario y el régimen sancionatorio tributario para el Municipio de Santa fe de Antioquia”. [Acuerdo municipal n. 053 de 2013].

Consejo Municipal de Urrao. (24 de agosto de 2014). Por medio del cual se expide la normatividad sustantiva, sancionatoria y procedimental aplicable a los ingresos tributarios del municipio de Urrao. [Acuerdo municipal n. ${ }^{\circ} 12$ de 2014].

Constitución Política de Colombia. [Const.]. (1991). Bogotá: Legis.

Corte Constitucional. (15 de octubre de 2003). Sentencia C-944 de 2003. [MP. Alfredo Beltrán Sierra].

Corte Constitucional. (22 de enero de 2004). Sentencia T-025 de 2004. [MP. Manuel José Cepeda].

Corte Constitucional. (22 de enero de 2004). Sentencia T- 025 de 2004. [MP. Manuel José Cepeda Espinosa].

Corte Constitucional. (16 de noviembre de 2010). Sentencia C-914 de 2010. [MP. Juan Carlos Henao Pérez]. 
Corte Constitucional. (6 de junio de 2014). Sentencia T-347 de 2014. [MP. Mauricio González Cuervo].

Corte Constitucional. (1. ${ }^{\circ}$ de diciembre de 2014). Sentencia T-911 de 2014. [MP. María Victoria Sáchica Méndez]

Corte Constitucional. (2 de diciembre de 2015). Sentencia C- 743 de 2015. [MP. Myriam Ávila Roldán].

Dirección de Apoyo Fiscal del Ministerio de Hacienda. (20 de mayo de 2005). n. ${ }^{\circ}$ 014042-05. [Subdirector de Fortalecimiento Institucional Territorial Luis Fernando Villota Quiñones].

Insignares, R., y Sánchez, M. (2010). El poder tributario: organización y estructura en el Estado colombiano. En J. Piza (Ed.), Curso de derecho tributario, procedimiento y régimen sancionatorio. Bogotá: Universidad Externado de Colombia.

Juzgado Primero Civil del Circuito Especializado en Restitución de Tierras de Santa Marta. (10 de septiembre de 2013). [Juez Fabián Arrieta Baena].

Marín, M. (2007). La estructura jurídica del tributo: el hecho generador. En R. Insignares, M. Marín, J. Piza y J. Zornoza, Curso de derechos fiscal. Tomo 1. Bogotá: Universidad Externado de Colombia.

Marín, M. (2008). Consideraciones previas sobre el régimen impositivo de las entidades territoriales. En J. Piza (Coord.), Régimen impositivo de las entidades territoriales en Colombia. Bogotá: Universidad Externado de Colombia.

Medina, A. (2015). Lección 10. La extinción de la deuda tributaria. En J. Piza (Ed.), La obligación tributaria y sus fundamentos constitucionales. Bogotá: Universidad Externado de Colombia.

Ministerio de Gobierno. (25 de abril de 1986). Por el cual se expide el Código de Régimen Municipal [Decreto Ley 1333 de 1986].

Ochoa, R. (2011). Bienes. Bogotá: Temis.

Parra, H. (2012). Los impuestos territoriales a la propiedad raíz en Colombia. Medellín: Centro de Estudios Tributarios de Antioquia (CETA).

Piza, J. (2010). Lección 11. Sistema tributario colombiano. En J. Piza (Ed.), Curso de derecho tributario, procedimiento y régimen sancionatorio. Bogotá: Universidad Externado de Colombia

Presidencia de la República. (20 de diciembre de 2011). Por el cual se reglamenta la Ley 1448 de 2011 y se dictan otras disposiciones. [Decreto 4800 de 2011]. DO: 48280.

Presidencia de la República. (20 de diciembre de 2011). Por el cual se reglamenta el Capítulo III del Título IV de la Ley 1448 de 2011 en relación con la restitución de tierras. [Decreto 4829 de 2011]. DO: 48280.

Tribunal Superior del Distrito Judicial de Antioquia, Sala Especializada en Restitución de Tierras, Sala Tercera. (11 de febrero de 2016) Sentencia 04. [Magistrado Sustanciador Benjamín de Jesús Yepes Puerta].

Unidad Administrativa Especial de Gestión de Restitución de Tierras Despojadas. (2013). Por el cual se adopta y se definen los lineamientos para la ejecución del Programa de Alivio de Pasivos. [Acuerdo n. 009 de 2013 ].

Unidad de Restitución de Tierras. (2014). Informe trimestral de gestión-Plan de acción a 30 de septiembre de 2014. Recuperado de https://www.restituciondetierras.gov.co/documents/10184/c364aba6-5722-4101-ba61c420017b20c7

Unidad de Restitución de Tierras. (s.f.). Mapas de microfocalización. Recuperado de http://uaegrtd.maps.arcgis. com/apps/Viewer/index.html?appid=d821d00317554732847758b2bc3496b4 